\title{
Demographics, Management, and In-Hospital Outcome of Hospitalized Acute Heart Failure Syndrome Patients in Contemporary Real Clinical Practice in Japan - Observations From the Prospective, Multicenter Kyoto Congestive Heart Failure (KCHF) Registry -
}

Hidenori Yaku, MD; Neiko Ozasa, MD; Takeshi Morimoto, MD; Yasutaka Inuzuka, MD; Yodo Tamaki, MD; Erika Yamamoto, MD; Yusuke Yoshikawa, MD; Takeshi Kitai, MD; Ryoji Taniguchi, MD; Moritake Iguchi, MD; Masashi Kato, MD; Mamoru Takahashi, MD; Toshikazu Jinnai, MD; Tomoyuki Ikeda, MD; Kazuya Nagao, MD; Takafumi Kawai, MD; Akihiro Komasa, MD; Ryusuke Nishikawa, MD; Yuichi Kawase, MD; Takashi Morinaga, MD;

Kanae Su, MD; Mitsunori Kawato, MD; Kenichi Sasaki, MD; Mamoru Toyofuku, MD; Yutaka Furukawa, MD; Yoshihisa Nakagawa, MD; Kenji Ando, MD; Kazushige Kadota, MD; Satoshi Shizuta, MD; Koh Ono, MD; Yukihito Sato, MD; Koichiro Kuwahara, MD; Takao Kato, MD; Takeshi Kimura, MD on behalf of the KCHF Study Investigators

Background: There is a scarcity of reports on the clinical characteristics and management practice in contemporary all-comer patients with acute decompensated heart failure (ADHF).

Methods and Results: The Kyoto Congestive Heart Failure (KCHF) registry is a prospective observational cohort study enrolling 4,056 consecutive patients who had hospital admission due to ADHF without any exclusion criteria between October 2014 and March 2016 in the 19 participating hospitals in Japan. Baseline characteristics, clinical presentations, management, and in-hospital outcomes were compared between heart failure (HF) with reduced left ventricular ejection fraction (LVEF; HFrEF, LVEF <40\%), HF with mid-range LVEF (HFmrEF, LVEF 40-49\%), and HF with preserved LVEF (HFpEF, LVEF $\geq 50 \%$ ). Of the 4,041 patients with documented LVEF, 1,744 (43\%) had HFpEF; 746 (19\%), HFmrEF; and 1,551 (38\%), HFrEF. The median age was 80 years (IQR, 72-86 years) in the entire population, and was higher with increasing LVEF $(\mathrm{P}<0.001)$. The in-hospital mortality rate was higher in the HFrEF than in the HFmrEF and HFpEF groups $(9.2 \%, 4.8 \%$, and $5.1 \%$, respectively, $\mathrm{P}<0.001)$.

Conclusions: This registry elucidated the clinical features and clinically relevant in-hospital outcomes in contemporary consecutive patients with ADHF in real-world clinical practice in Japan. When classified by LVEF, significant differences in characteristics and in-hospital outcomes existed between patients with HFrEF, HFmrEF, and HFpEF.

Key Words: Cohort study; Heart failure; Hospitalization; Mid-range ejection fraction; Mortality

$\mathbf{H}$ eart failure $(\mathrm{HF})$ is a major public health burden worldwide that is associated with high costs. ${ }^{1,2}$ The number of patients with acute decompensated heart failure (ADHF) continues to increase annually. ${ }^{3-5}$ Repeat hospitalization is a major issue in patients with ADHF, leading to high mortality rates ${ }^{2}$ and a decline in quality of life (QOL). There are several previous large-scale registries evaluating the demographics, management, and clinical outcomes of patients with ADHF in various geographical area. ${ }^{6-12}$ Recently, however, the population in the developed countries, Japan in particular, has been aging rapidly, leading to a marked increase in new-onset HF.,12-14 The demographics, management, and clinical outcomes of patients with ADHF in this rapidly aging society might be much different from those reported in the previous ADHF registries. Particularly, evaluation of social factors would

Received December 18, 2017; revised manuscript received July 12, 2018; accepted August 6, 2018; released online September 26, 2018 Time for primary review: 29 days

Department of Cardiovascular Medicine, Kyoto University Graduate School of Medicine, Kyoto (H.Y., N.O., Y.Y., S.S., K.O., T. Kato, T. Kimura); Department of Clinical Epidemiology, Hyogo College of Medicine, Hyogo (T. Morimoto); Department of Cardiovascular Medicine, Shiga Medical Center for Adults, Shiga (Y.I.); Division of Cardiology, Tenri Hospital, Nara (Y.T., Y.N.), Japan; Department Cardiology Division, Massachusetts General Hospital and Harvard Medical School, Boston, MA (E.Y.), USA; Department of Cardiovascular Medicine, Kobe City Medical Center General Hospital, Hyogo (T. Kitai, Y.F.); Department of Cardiology, Hyogo Prefectural Amagasaki General Medical Center, Hyogo (R.T., Y.S.); National Hospital Organization Kyoto Medical Center, Kyoto (M.I.); Mitsubishi Kyoto Hospital, Kyoto (M. Kato); Shimabara Hospital, Kyoto (M. Takahashi);

(Footnote continued the next page.) 
be important in elderly patients with ADHF. Therefore, we established the multicenter Kyoto Congestive Heart Failure (KCHF) registry enrolling consecutive hospitalized ADHF patients and collecting comprehensive information including social factors, in order to explore the recent trends in the demographics, management and clinical outcomes of patients with ADHF. In this first report from the KCHF registry, we compared the baseline characteristics, clinical presentations, management, and in-hospital outcomes based on left ventricular ejection fraction (LVEF), because HF patients with borderline (mid-range) LVEF (HFmrEF) have not yet been adequately characterized as compared with HF patients with reduced LVEF (HFrEF) or with preserved LVEF (HFpEF).

\section{Methods}

\section{Subjects}

The KCHF registry is a physician-initiated, prospective, observational, multicenter cohort study enrolling the consecutive patients admitted to hospitals due to ADHF for the first time between October 2014 and March 2016 in the 19 secondary and tertiary hospitals, including rural and urban, large and small hospitals, in Tokai, Kinki, Chugoku, and Kyushu districts in Japan (Appendix S1; Figure S1). The overall design of the KCHF study has been previously described in detail. ${ }^{15} \mathrm{We}$ enrolled all patients with ADHF as defined by the modified Framingham criteria, who were admitted to the participating centers, ${ }^{\mathbf{1 6}, 17}$ and those who underwent HF-specific treatment involving i.v. drugs $\leq 24 \mathrm{~h}$ after hospital presentation. In the present study, we compared the baseline characteristics, clinical presentation, management, and in-hospital clinical outcomes between patients with HFrEF, HFmrEF, or HFpEF in the KCHF registry. In addition, we compared the patients by dividing them into 4 quartiles of age, to clarify the impact of LVEF on their characteristics in each category of age.

\section{Ethics}

The study protocol was approved by the ethics committees at Kyoto University Hospital (local identifier: E2311) and at all participating hospitals (details given in Supplementary File 1). This study was registered with UMIN (UMIN identifier: UMIN000015238).

\section{Data Collection and Definitions}

The attending physicians or research assistants at each participating hospital collected comprehensive data on patient demographics, medical history, underlying heart disease, pre-hospital activities, socioeconomic status, signs, symptoms, medication, laboratory test, electrocardiogram, echocardiography, acute management during emergency room, status at discharge, and clinical events during the index hospitalization. The signs and symptoms were recorded at 4 time points: at hospital arrival; admission; $24 \mathrm{~h}$ after hospital arrival (data not shown); and discharge.
Laboratory tests were performed at hospital presentation and at the nearest time to discharge. LVEF was measured in a detailed assessment in the echocardiography department, hospital ward, and, in some cases, in the emergency department. We did not adopt LVEF data only with a quick survey. The timing was variable among the patients, but we adopted the data in the earliest echocardiography as possible after admission. LVEF was measured using the biplane modified Simpson's method. HF was classified according to LVEF, as HFrEF (LVEF < $40 \%$ ), HFmrEF (LVEF $40-49 \%$ ), and HFpEF (LVEF $\geq 50 \%$ ). Other definitions for the baseline factors were provided in Supplementary File 1. The clinical events included in-hospital mortality (death from any cause, cardiovascular death, and noncardiovascular death), acute coronary events, arrhythmic events, stroke, and bleeding events during hospitalization. In addition, deterioration of HF during the index hospitalization and deteriorated renal function were adjudicated as clinical events. Worsening HF (WHF) during hospitalization was defined as additional i.v. drug treatment for HF, hemodialysis, or mechanical circulatory or respiratory support, occurring $>24 \mathrm{~h}$ after therapy initiation. ${ }^{18}$ Worsening renal function (WRF) was defined as $>0.3 \mathrm{mg} / \mathrm{dL}$ increase in serum creatinine during the index hospitalization. ${ }^{19-21}$ Definitions for other clinical events are provided in Supplementary File 1.

To ensure the quality of the data, a study management committee met every 2 months. For each meeting, a study management committee chose randomly 2 or 3 hospitals and evaluated the quality of the input. ${ }^{15}$

\section{Statistical Analysis}

Categorical variables are presented as $\mathrm{n}(\%)$. Continuous variables are presented as mean $\pm \mathrm{SD}$ or median (IQR). Comparisons between patients with HFrEF, HFmrEF, or HFpEF, and comparisons between the 4 quartiles by age, were performed using chi-squared test for categorical variables and 1-way ANOVA or Kruskal-Wallis test for continuous variables. To determine the differences between HFrEF, HFmrEF, and HFpEF, we performed the Bonferroni post-hoc test in the entire cohort and in each quartile of age. All statistical analysis was conducted with JMP 13.0 (SAS Institute, Cary, NC, USA). Two-tailed $\mathrm{P}<0.05$ was considered statistically significant.

\section{Results}

\section{Patient Background}

A total of 4,056 patients were enrolled in this registry. There were 1,744 patients $(43 \%)$ with HFpEF, 746 patients $(19 \%)$ with HFmrEF, and 1,551 patients $(38 \%)$ with HFrEF after excluding 15 patients with missing LVEF. Echocardiography was performed after a median of 1 day of admission (IQR, $0-6$ hospital days), and $73 \%$ of the entire cohort were assessed for $\mathrm{LVEF} \leq 5$ days after admission. The median age was 80 years (IQR, 72-86 years; range,

Japanese Red Cross Otsu Hospital, Shiga (T.J.); Hikone Municipal Hospital, Shiga (T.I.); Osaka Red Cross Hospital, Osaka (K.N.); Kishiwada City Hospital, Osaka (T. Kawai); Kansai Electric Power Hospital, Osaka (A.K.); Shizuoka General Hospital, Shizuoka (R.N.); Kurashiki Central Hospital, Okayama (Y.K., K. Kadota); Kokura Memorial Hospital, Fukuoka (T. Morinaga, K.A.); Japanese Red Cross Wakayama Medical Center, Wakayama (K. Su, M. Toyofuku); Nishikobe Medical Center, Hyogo (M. Kawato); Kitano Hospital, Osaka (K. Sasaki); and Department of Cardiovascular Medicine, Shinshu University Graduate School of Medicine, Matsumoto (K. Kuwahara), Japan

Mailing address: Takao Kato, MD, Department of Cardiovascular Medicine, Graduate School of Medicine, Kyoto University, 54 Shogoin Kawahara-cho, Sakyo-ku, Kyoto606-8507, Japan. E-mail: tkato75@kuhp.kyoto-u.ac.jp

ISSN-1346-9843 All rights are reserved to the Japanese Circulation Society. For permissions, please e-mail: cj@j-circ.or.jp 


\begin{tabular}{|c|c|c|c|c|c|c|c|c|}
\hline & \multirow{2}{*}{$\begin{array}{c}\text { Entire } \\
\text { cohort } \\
(n=4,056)\end{array}$} & \multirow{2}{*}{$\begin{array}{c}\text { HFrEF } \\
(n=1,551)\end{array}$} & \multirow{2}{*}{$\begin{array}{l}\text { HFmrEF } \\
(n=746)\end{array}$} & \multirow{2}{*}{$\begin{array}{l}\text { HFpEF } \\
(n=1,744)\end{array}$} & \multicolumn{4}{|c|}{ P-value } \\
\hline & & & & & & $\begin{array}{l}\text { HFmrEF } \\
\text { vs. HFrEF }\end{array}$ & $\begin{array}{l}\text { HFpEF } \\
\text { vs. HFrEF }\end{array}$ & $\begin{array}{l}\text { HFmrEF } \\
\text { vs. HFpEF }\end{array}$ \\
\hline \multicolumn{9}{|l|}{ Demographics } \\
\hline Age (years) & $80(72-86)$ & $77(67-85)$ & $80(72-86)$ & $82(76-88)$ & $<0.001$ & $<0.001$ & $<0.001$ & $<0.001$ \\
\hline Age $\geq 85$ years & $1,333(33)$ & $394(25)$ & $243(33)$ & $689(40)$ & $<0.001$ & $<0.001$ & $<0.001$ & 0.003 \\
\hline Female & $1,818(45)$ & $521(34)$ & $301(40)$ & $989(57)$ & $<0.001$ & 0.005 & $<0.001$ & $<0.001$ \\
\hline $\mathrm{BMI}\left(\mathrm{kg} / \mathrm{m}^{2}\right)$ & $22.8 \pm 4.5$ & $22.8 \pm 4.6$ & $22.7 \pm 4.3$ & $22.9 \pm 4.4$ & 0.57 & & & \\
\hline $\mathrm{BMI}<22 \mathrm{~kg} / \mathrm{m}^{2}$ & $1,787(47)$ & $705(48)$ & $326(46)$ & $753(46)$ & 0.62 & & & \\
\hline \multicolumn{9}{|l|}{ Medical history } \\
\hline Prior hospitalization due to HF & $1,442(36)$ & 597 (39) & $248(34)$ & $593(35)$ & 0.004 & 0.03 & 0.01 & 1.00 \\
\hline $\mathrm{AF} / \mathrm{AFL}$ & $1,681(41)$ & $487(31)$ & $310(42)$ & $878(50)$ & $<0.001$ & $<0.001$ & $<0.001$ & $<0.001$ \\
\hline Hypertension & $2,909(72)$ & $1,017(66)$ & $569(76)$ & $1,310(75)$ & $<0.001$ & $<0.001$ & $<0.001$ & 1.00 \\
\hline Diabetes mellitus & $1,510(37)$ & $626(40)$ & $300(40)$ & $578(33)$ & $<0.001$ & 1.00 & $<0.001$ & 0.002 \\
\hline Prior MI & $908(22)$ & $492(32)$ & $223(30)$ & $190(11)$ & $<0.001$ & 1.00 & $<0.001$ & $<0.001$ \\
\hline Current smoking & $476(12)$ & $233(15)$ & $103(14)$ & $139(8.1)$ & $<0.001$ & 1.00 & $<0.001$ & $<0.001$ \\
\hline Prior stroke/TIA & $662(16)$ & $225(15)$ & $126(17)$ & $306(18)$ & 0.054 & & & \\
\hline VT/VF & $165(4.1)$ & $123(7.9)$ & $18(2.4)$ & $23(1.3)$ & $<0.001$ & $<0.001$ & $<0.001$ & 0.15 \\
\hline CKD & $1,809(45)$ & $678(44)$ & $352(47)$ & $770(44)$ & 0.27 & & & \\
\hline Dementia & 770 (19) & $262(17)$ & $134(18)$ & $370(21)$ & 0.005 & 1.00 & 0.005 & 0.19 \\
\hline \multicolumn{9}{|l|}{ Social background } \\
\hline Poor medical adherence & $674(17)$ & 298 (19) & $126(17)$ & $249(14)$ & $<0.001$ & 0.54 & $<0.001$ & 0.29 \\
\hline Employed & $510(13)$ & $281(18)$ & $92(12)$ & $137(7.9)$ & $<0.001$ & 0.001 & $<0.001$ & 0.001 \\
\hline Public assistance & $234(5.8)$ & $106(6.8)$ & $46(6.2)$ & $82(4.7)$ & 0.03 & 1.00 & 0.03 & 0.39 \\
\hline \multicolumn{9}{|l|}{ Lifestyle } \\
\hline Single & $866(21)$ & $348(22)$ & $161(22)$ & $355(20)$ & 0.34 & & & \\
\hline With a partner only & $1,720(42)$ & $692(45)$ & $344(46)$ & $677(39)$ & $<0.001$ & 1.00 & 0.002 & 0.002 \\
\hline $\begin{array}{l}\text { Institution for aged or } \\
\text { hospital }\end{array}$ & $281(7.0)$ & $102(6.6)$ & $49(6.6)$ & $129(7.4)$ & 0.59 & & & \\
\hline \multicolumn{9}{|l|}{ Daily life activities } \\
\hline Ambulatory & $3,149(78)$ & $1,246(81)$ & $595(80)$ & $1,299(75)$ & $<0.001$ & 1.00 & $<0.001$ & 0.02 \\
\hline Use of wheelchair (outdoor only) & $305(7.6)$ & $92(6.0)$ & $58(7.8)$ & $153(8.9)$ & 0.01 & 0.30 & 0.006 & 1.00 \\
\hline $\begin{array}{l}\text { Use of wheelchair } \\
\text { (outdoor and indoor) }\end{array}$ & $388(9.7)$ & $126(8.2)$ & $62(8.4)$ & $198(11)$ & 0.003 & 1.00 & 0.006 & 0.07 \\
\hline Bedridden & $172(4.3)$ & $69(4.5)$ & 25 (3.4) & 77 (4.5) & 0.41 & & & \\
\hline
\end{tabular}

Data given as $n(\%)$, mean $\pm \mathrm{SD}$, or median (IQR). AF/AFL, atrial fibrillation/flutter; BMI, body mass index; CKD, chronic kidney disease; HF, heart failure; HFmrEF, heart failure with mid-range ejection fraction; HFpEF, heart failure with preserved ejection fraction; HFrEF, heart failure with reduced ejection fraction; ICD, implantable cardioverter defibrillator; MI, myocardial infarction; TIA, transient ischemic attack; VT/VF, ventricular tachycardia/fibrillation.

18-105 years) in the entire cohort, and trended to be higher with increasing LVEF (HFrEF, 77 years; HFmrEF, 80 years; HFpEF, 82 years; Table 1; Figure S2). Women accounted for $45 \%$ of the patients, and the proportion of women was higher with increasing LVEF (HFrEF, 33\%; $\mathrm{HFmrEF}, 40 \%$; and $\mathrm{HFpEF}, 57 \%$; Table 1). In the entire cohort, the proportion of patients with body mass index $<22 \mathrm{~kg} / \mathrm{m}^{2}$ was $47 \%$. HFrEF patients more often had a history of $\mathrm{HF}$ hospitalization than $\mathrm{HFmrEF}$ and $\mathrm{HFpEF}$ patients (Figure A). HFpEF patients less often had prior myocardial infarction than $\mathrm{HFrEF}$ and HFmrEF patients (Figure B), and HFrEF patients less often had hypertension than HFmrEF and HFpEF patients (Figure C). The prevalence of atrial fibrillation/flutter (AF/AFL; Figure D) was higher with increasing LVEF (Table 1). There were significant differences in social background, living status, and daily life activities between the 3 groups (Table 1). When we compared the patients by dividing them into 4 quartiles of age in each category of LVEF (Tables S1,S2), the trend in the prevalence of female sex and AF/AFL was generally consistent with that in the entire cohort. Other background data are listed in Table S3.

The most common causes of HF were coronary artery disease (CAD; 33\%), followed by hypertensive heart disease $(24 \%)$, valvular heart disease $(20 \%)$, and primary cardiomyopathy (15\%; Table 2). CAD and cardiomyopathy were more prevalent in HFrEF and HFmrEF patients than in HFpEF patients, while hypertensive heart disease and valvular heart disease were more prevalent in HFpEF and HFmrEF patients than in HFrEF patients in the entire cohort (Table 2) and when stratified by age (Tables S1,S2).

\section{Clinical Presentation}

At presentation, heart rate was higher in HFrEF and in HFmrEF patients than in HFpEF patients (Figure E), while systolic blood pressure (SBP) was higher in HFpEF and HFmrEF patients than in HFrEF patients (Table 3; Figure F). C-reactive protein level was not significantly different between the 3 groups. A total of $67 \%$ had anemia and $13 \%$ had hyponatremia (Table 3). Anemia at presentation was 


\section{A. De novo HF}

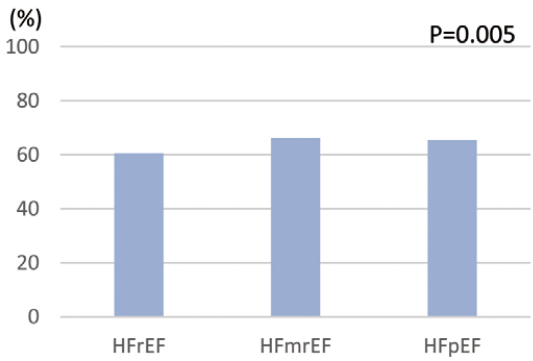

\section{Hypertension}

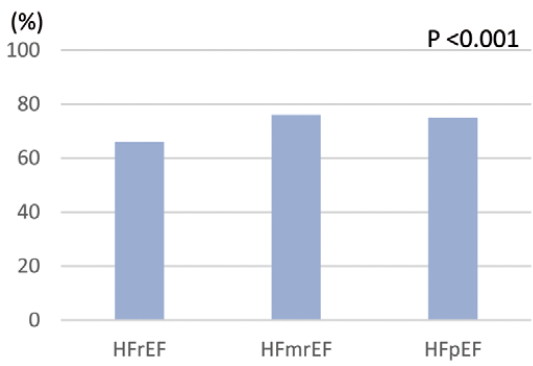

\section{E. Heart rate}

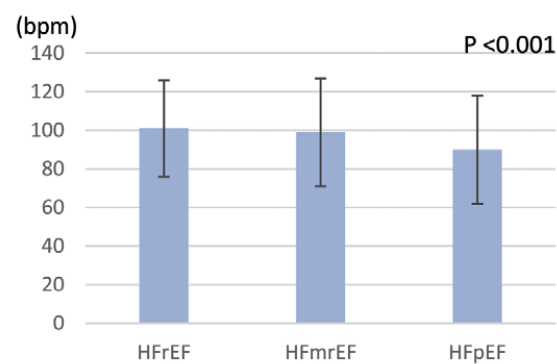

\section{G. Orthopnea}

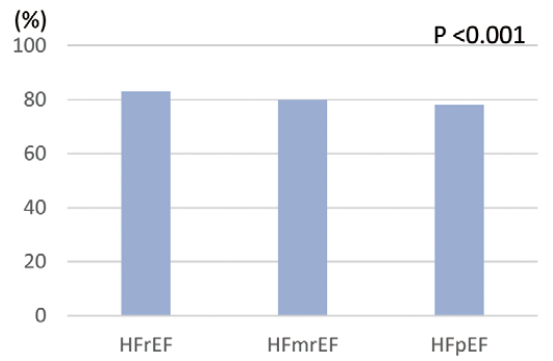

\section{B. Prior MI}

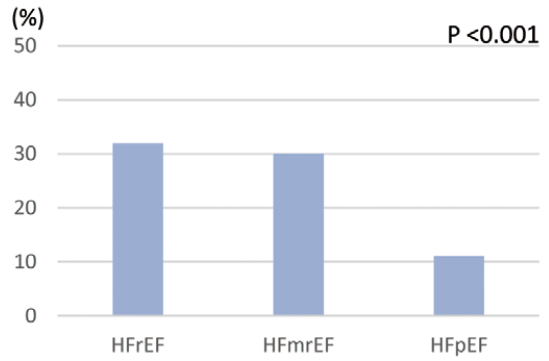

\section{AFIAFL rhythm}

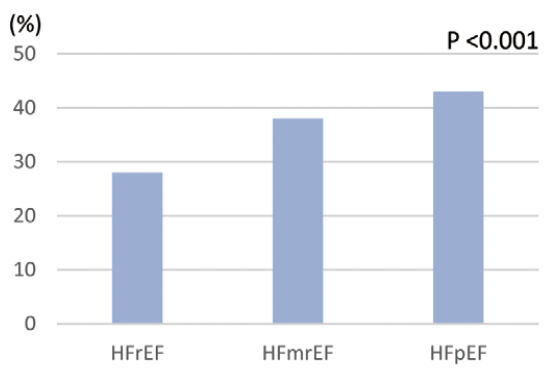

\section{F. Systolic BP}

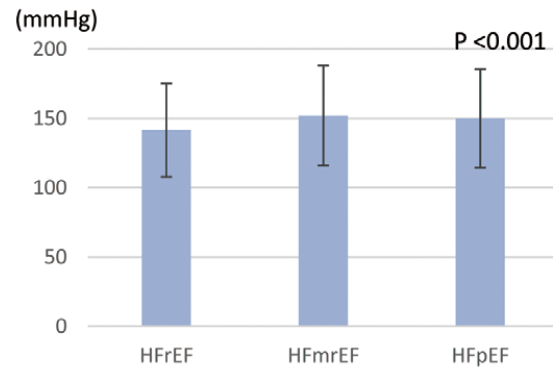

\section{H. Systolic BP $<100 \mathrm{mmHg}$}

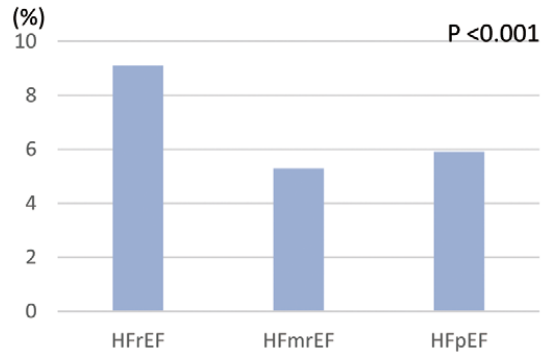

Figure. Rate of $(\mathbf{A})$ de novo heart failure (HF), (B) prior myocardial infarction (MI), (C) hypertension, (D) atrial fibrillation/flutter (AF/AFL) at presentation, and (E) heart rate, $(\mathbf{F})$ systolic blood pressure (SBP), (G) orthopnea, and $(\mathbf{H}) \mathrm{SBP}<100 \mathrm{mmHg}$ at presentation in HF patients with reduced left ventricular ejection fraction (LVEF; HFrEF), HF with mid-range LVEF (HFmrEF), and HF with preserved LVEF (HFpEF).

more prevalent with increasing LVEF, while brain natriuretic polypeptide (BNP) was higher with decreasing LVEF (Table 3). The trend in anemia and BNP, when stratified by age, was generally consistent with that in the entire cohort (Tables S1,S2). Renal function as evaluated with estimated glomerular filtration rate was not different between the 3 groups (Table 3).

\section{Emergency Room and In-Hospital Management}

Upon arrival at the emergency department, intubation and inotrope use were more prevalent with decreasing LVEF, while nitroglycerine was most often used in HFmrEF patients (Tables 3,S3). Although the prevalence of orthopnea at presentation was high in the 3 groups (Figure $\mathbf{G})$, relief in orthopnea was observed in $32 \%$ of the patients following treatment in the emergency room. Coronary angiography 


\begin{tabular}{|c|c|c|c|c|c|c|c|c|}
\hline \multirow[b]{2}{*}{ Subgroups } & \multirow{2}{*}{$\begin{array}{c}\text { Entire } \\
\text { cohort } \\
(n=4,056)\end{array}$} & \multirow{2}{*}{$\begin{array}{c}\text { HFrEF } \\
(n=1,551)\end{array}$} & \multirow{2}{*}{$\begin{array}{c}\text { HEmrEF } \\
(n=746)\end{array}$} & \multirow{2}{*}{$\begin{array}{c}\text { HFpEF } \\
(n=1,744)\end{array}$} & \multicolumn{4}{|c|}{ P-value } \\
\hline & & & & & & $\begin{array}{l}\text { HFmrEF } \\
\text { vs. HFrEF }\end{array}$ & $\begin{array}{c}\text { HFpEF } \\
\text { vs. HFrEF }\end{array}$ & $\begin{array}{l}\text { HFmrEF } \\
\text { vs. HFpEF }\end{array}$ \\
\hline CAD & $1,327(33)$ & $708(46)$ & $301(40)$ & $312(18)$ & $<0.001$ & 0.08 & $<0.001$ & $<0.001$ \\
\hline Non-ACS & $1,088(27)$ & 598 (39) & $243(33)$ & $242(14)$ & $<0.001$ & & & \\
\hline ACS & 239 (5.9) & $110(7.1)$ & $58(7.8)$ & $70(4.0)$ & $<0.001$ & & & \\
\hline Hypertensive heart disease & $985(24)$ & $196(13)$ & $189(25)$ & 597 (34) & $<0.001$ & $<0.001$ & $<0.001$ & $<0.001$ \\
\hline Cardiomyopathy & $608(15)$ & $432(28)$ & 77 (10) & $97(2.4)$ & $<0.001$ & $<0.001$ & $<0.001$ & $<0.001$ \\
\hline DCM & $434(11)$ & 363 (23) & $48(6.4)$ & $26(1.5)$ & $<0.001$ & & & \\
\hline $\mathrm{HCM}$ & $59(1.5)$ & $6(0.4)$ & $10(1.3)$ & $42(2.4)$ & $<0.001$ & & & \\
\hline DHCM & $27(0.7)$ & $22(1.4)$ & $3(0.4)$ & $2(0.1)$ & $<0.001$ & & & \\
\hline Others & $88(2.2)$ & $45(2.9)$ & $16(2.1)$ & $27(1.6)$ & 0.03 & & & \\
\hline Valvular heart disease & $819(20)$ & $161(10)$ & $146(20)$ & $510(29)$ & $<0.001$ & $<0.001$ & $<0.001$ & $<0.001$ \\
\hline Aortic stenosis & $297(7.3)$ & $63(4.1)$ & $58(7.8)$ & $176(10)$ & $<0.001$ & & & \\
\hline Aortic regurgitation & $104(2.6)$ & $32(2.1)$ & $29(3.9)$ & $41(2.4)$ & 0.03 & & & \\
\hline Mitral stenosis & $36(0.9)$ & $4(0.3)$ & $4(0.5)$ & $28(1.6)$ & $<0.001$ & & & \\
\hline Mitral regurgitation & $250(6.1)$ & $35(2.3)$ & $36(4.8)$ & $179(10)$ & $<0.001$ & & & \\
\hline Tricuspid regurgitation & $41(1.0)$ & $3(0.2)$ & $5(0.7)$ & $33(1.9)$ & $<0.001$ & & & \\
\hline Prosthetic valve dysfunction & $91(2.2)$ & $24(1.5)$ & $14(1.9)$ & $53(3.0)$ & 0.01 & & & \\
\hline Other heart disease & $297(7.3)$ & & & & & & & \\
\hline Arrhythmia & $188(4.6)$ & $24(1.5)$ & $22(3.0)$ & $141(8.1)$ & $<0.001$ & 0.07 & $<0.001$ & $<0.001$ \\
\hline Bradycardia & $64(1.6)$ & $4(0.3)$ & $3(0.4)$ & $56(3.2)$ & $<0.001$ & & & \\
\hline Tachycardia & $124(3.1)$ & $20(1.3)$ & $19(2.6)$ & $85(4.9)$ & $<0.001$ & & & \\
\hline $\mathrm{CHD}$ & $15(0.4)$ & 0 & $2(0.3)$ & $12(0.7)$ & 0.003 & & & \\
\hline Constrictive pericarditis & $4(0.1)$ & 0 & 0 & $4(0.2)$ & 0.07 & & & \\
\hline Others & $110(2.7)$ & $30(1.9)$ & $9(1.2)$ & $71(4.1)$ & $<0.001$ & & & \\
\hline
\end{tabular}

Data given as $\mathrm{n}(\%)$. ACS, acute coronary syndrome; CAD, coronary artery disease; CHD, congenital heart disease; DCM, dilated cardiomyopathy; DHCM, dilated phase of hypertrophic cardiomyopathy; HCM, hypertrophic cardiomyopathy. Other abbreviations as in Table 1.

and percutaneous coronary intervention were more often performed in HFrEF and in HFmrEF patients than in HFpEF patients, while pacemaker implantation was performed more frequently in $\mathrm{HFpEF}$ patients than in HFrEF and HFmrEF patients (Table 3).

\section{In-Hospital Outcome}

Of the 4,056 hospitalized patients, $271(6.7 \%)$ died in hospital. The in-hospital mortality rate was lower in the $\mathrm{HFmrEF}$ and HFpEF groups than in the HFrEF group $(4.8 \%, 5.1 \%$, and $9.2 \%$, respectively, $\mathrm{P}<0.001$; Table 4). The prevalence of WHF during hospitalization was higher with decreasing LVEF (25\% in HFrEF, 19\% in HFmrEF, and $15 \%$ in HFpEF), while the prevalence of WRF was high in the HFmrEF group (41\%) as well as in the HFpEF group (Table 4). The median length of hospital stay was 16 days (IQR, 11-25 days) without any significant difference across the 3 groups (Table 4 ).

\section{Clinical Profile at Hospital Discharge}

The signs and symptoms of congestion, such as dyspnea, rales, and jugular venous distention, improved at discharge in most of the patients (Tables 5,S4). The median change of body weight during hospitalization was $-3.0 \mathrm{~kg}$ (IQR, -5.8 to $-1.0 \mathrm{~kg}$ ) without any significant difference across the 3 groups. The prevalence of hyponatremia was $13 \%$ at discharge without significant difference across the 3 groups, while the prevalence of anemia increased with increasing LVEF (Table 5).

The median number of prescribed drugs at discharge was 8 (IQR, 6-11) without any significant difference across the 3 groups. Loop diuretics were prescribed in $81 \%$ of patients without significant difference across the 3 groups. Beta-blockers and renin-angiotensin-aldosterone system inhibitors were more frequently prescribed in patients with HFrEF and HFmrEF than in patients with HFpEF, while calcium channel blockers were more often prescribed with increasing LVEF. Tolvaptan and amiodarone were more often prescribed in patients with HFrEF than in patients with HFmrEF and HFpEF (Table 5). The prescription trend for $\beta$-blockers, calcium channel blockers, and amiodarone in the entire cohort was consistent with that when stratified by age (Table S1).

The proportion of patients discharged to their home was $82 \%$, and the proportion of ambulatory patients decreased at discharge (Table 5). The proportion of ambulatory patients was greater in HFrEF patients than in HFmrEF and HFpEF patients. The use of long-term care insurance included care required in $34 \%$ of patients, support required in $14 \%$ of patients, and plan to use it in $5.9 \%$ of patients (Table 5). The proportion of patients with care required was higher with increasing LVEF, but the trend in ambulatory patients and care planning was not observed when stratified by age (Table S1).

\section{Discussion}

Registry data on patients with ADHF in real clinical practice would have a great influence on the management for ADHF and clarify the unmet needs for the clinical trials evaluating new treatment. Most previous hospital-based registries in Japan, as well as in other countries, however, 


\begin{tabular}{|c|c|c|c|c|c|c|c|c|}
\hline \multirow[b]{3}{*}{ Vital signs at presentation } & \multirow{2}{*}{$\begin{array}{c}\text { Entire } \\
\text { cohort } \\
(n=4,056)\end{array}$} & \multirow{2}{*}{$\begin{array}{c}\text { HFrEF } \\
(n=1,551)\end{array}$} & \multirow{2}{*}{$\begin{array}{l}\text { HFmrEF } \\
(n=746)\end{array}$} & \multirow{2}{*}{$\begin{array}{l}\text { HFpEF } \\
(n=1,744)\end{array}$} & \multicolumn{4}{|c|}{ P-value } \\
\hline & & & & & & $\begin{array}{l}\text { HFmrEF } \\
\text { vs. HFrEF }\end{array}$ & $\begin{array}{l}\text { HFpEF } \\
\text { vs. HFrEF }\end{array}$ & $\begin{array}{l}\text { HFmrEF } \\
\text { vs. HFpEF }\end{array}$ \\
\hline & & & & & & & & \\
\hline Heart rate (beats/min) & $96 \pm 28$ & $101 \pm 25$ & $99 \pm 28$ & $90 \pm 28$ & $<0.001$ & 0.75 & $<0.001$ & $<0.001$ \\
\hline $\mathrm{SBP}(\mathrm{mmHg})$ & $147 \pm 35$ & $141 \pm 34$ & $152 \pm 36$ & $150 \pm 36$ & $<0.001$ & $<0.001$ & $<0.001$ & 0.54 \\
\hline$>140$ & $2,179(54)$ & $741(48)$ & $440(59)$ & $988(57)$ & $<0.001$ & & & \\
\hline $100-140$ & $1,581(39)$ & $665(43)$ & $264(36)$ & $647(37)$ & $<0.001$ & & & \\
\hline$<100$ & $282(7.0)$ & $141(9.1)$ & $39(5.3)$ & $102(5.9)$ & $<0.001$ & & & \\
\hline $\mathrm{BT} \geq 37.5^{\circ} \mathrm{C}$ & $257(6.6)$ & $75(5.1)$ & $51(7.2)$ & $130(7.7)$ & $<0.001$ & 0.15 & 0.008 & 1.00 \\
\hline \multicolumn{9}{|l|}{ Rhythms at presentation } \\
\hline Sinus rhythm & $2,274(56)$ & $1,006(65)$ & $414(56)$ & $845(49)$ & $<0.001$ & $<0.001$ & $<0.001$ & 0.004 \\
\hline AF/AFL & $1,453(36)$ & 427 (28) & $280(38)$ & $743(43)$ & $<0.001$ & $<0.001$ & $<0.001$ & 0.04 \\
\hline \multicolumn{9}{|l|}{ Admission laboratory data } \\
\hline $\mathrm{BNP}(\mathrm{pg} / \mathrm{mL})$ & $\begin{array}{c}721 \\
(398-1,308)\end{array}$ & $\begin{array}{c}994 \\
(588-1,704)\end{array}$ & $\begin{array}{c}780 \\
(453-1,297)\end{array}$ & $\begin{array}{c}499 \\
(284-892)\end{array}$ & $<0.001$ & $<0.001$ & $<0.001$ & $<0.001$ \\
\hline NT-pro BNP (pg/mL) & $\begin{array}{c}5,830 \\
(2,721- \\
13,242)\end{array}$ & $\begin{array}{c}7,384 \\
(3,433- \\
16,398)\end{array}$ & $\begin{array}{c}6,270 \\
(2,716- \\
18,300)\end{array}$ & $\begin{array}{c}4,890 \\
(2,277- \\
9,849)\end{array}$ & $<0.001$ & 1.00 & $<0.001$ & 0.03 \\
\hline Creatinine (mg/dL) & $\begin{array}{c}1.1 \\
(0.8-1.6)\end{array}$ & $\begin{array}{c}1.2 \\
(0.9-1.7)\end{array}$ & $\begin{array}{c}1.1 \\
(0.8-1.7)\end{array}$ & $\begin{array}{c}1.1 \\
(0.8-1.6)\end{array}$ & $<0.001$ & 1.00 & $<0.001$ & 0.09 \\
\hline eGFR $\left(\mathrm{mL} / \mathrm{min} / 1.73 \mathrm{~m}^{2}\right)$ & $\begin{array}{c}44 \\
(28-60)\end{array}$ & $\begin{array}{c}44 \\
(29-60)\end{array}$ & $\begin{array}{c}45 \\
(26-62)\end{array}$ & $\begin{array}{c}43 \\
(29-59)\end{array}$ & 0.30 & & & \\
\hline eGFR $<30 \mathrm{~mL} / \mathrm{min} / 1.73 \mathrm{~m}^{2}$ & $1,118(28)$ & $407(26)$ & $219(29)$ & $484(28)$ & 0.30 & & & \\
\hline Albumin $(\mathrm{g} / \mathrm{dL})$ & $3.5 \pm 0.5$ & $3.5 \pm 0.5$ & $3.5 \pm 0.5$ & $3.4 \pm 0.5$ & 0.004 & 0.07 & 0.002 & 1.00 \\
\hline Sodium (mEq/L) & $139 \pm 4.3$ & $139 \pm 4.4$ & $139 \pm 4.5$ & $139 \pm 4.2$ & 0.052 & & & \\
\hline Hyponatremia $^{\dagger}$ & $519(13)$ & $208(14)$ & $86(12)$ & $224(13)$ & 0.45 & & & \\
\hline Hemoglobin (g/dL) & $11.5 \pm 2.3$ & $12.2 \pm 2.4$ & $11.5 \pm 2.2$ & $10.9 \pm 2.2$ & $<0.001$ & $<0.001$ & $<0.001$ & $<0.001$ \\
\hline Anemia $^{\ddagger}$ & $2,705(67)$ & $878(57)$ & $506(68)$ & $1,313(75)$ & $<0.001$ & $<0.001$ & $<0.001$ & $<0.001$ \\
\hline \multicolumn{9}{|l|}{$\begin{array}{l}\text { Management in the emergency } \\
\text { room }\end{array}$} \\
\hline Respiratory management & $2,986(74)$ & $1,114(72)$ & $552(74)$ & $1,307(75)$ & 0.12 & & & \\
\hline Oxygen inhalation & $2,355(58)$ & $854(55)$ & $418(56)$ & $1,073(62)$ & $<0.001$ & & & \\
\hline NPPV & $556(14)$ & $221(14)$ & $119(16)$ & $213(12)$ & 0.03 & & & \\
\hline Intubation & $75(1.8)$ & $39(2.5)$ & $15(2.0)$ & $21(1.2)$ & 0.02 & & & \\
\hline Nitroglycerin & $741(18)$ & $255(16)$ & $172(23)$ & $312(18)$ & $<0.001$ & $<0.001$ & 0.81 & 0.008 \\
\hline Furosemide & $2,052(51)$ & $783(50)$ & $353(47)$ & $906(52)$ & 0.11 & & & \\
\hline Inotropes & $155(3.8)$ & $95(6.1)$ & $24(3.2)$ & $33(1.9)$ & $<0.001$ & 0.01 & $<0.001$ & \\
\hline \multicolumn{9}{|l|}{$\begin{array}{l}\text { I.v. drugs } \leq 24 \mathrm{~h} \text { after hospital } \\
\text { presentation }\end{array}$} \\
\hline Furosemide & $3,400(84)$ & $1,276(83)$ & $616(83)$ & $1,495(86)$ & 0.02 & 1.00 & 0.02 & 0.14 \\
\hline \multicolumn{9}{|l|}{ Vasodilators } \\
\hline Carperitide & $1,487(37)$ & $588(38)$ & $286(38)$ & $605(35)$ & 0.09 & & & \\
\hline Nitrates & $1,002(25)$ & $363(23)$ & $220(30)$ & $417(24)$ & 0.004 & 0.005 & 1.00 & 0.01 \\
\hline Nicardipine & $251(6.2)$ & $82(5.3)$ & $53(7.1)$ & $115(6.6)$ & 0.15 & & & \\
\hline Inotropes & $657(16)$ & $415(27)$ & $92(12)$ & $145(8.3)$ & $<0.001$ & $<0.001$ & $<0.001$ & 0.005 \\
\hline Heparin & $1,113(27)$ & $467(30)$ & $228(31)$ & $417(24)$ & $<0.001$ & 1.00 & $<0.001$ & 0.002 \\
\hline Landiolol & $95(2.3)$ & 48 (3.1) & $16(2.1)$ & $31(1.8)$ & 0.04 & 0.59 & 0.04 & 1.00 \\
\hline \multicolumn{9}{|l|}{ Procedural interventions } \\
\hline Coronary angiography & $1,262(31)$ & $588(38)$ & $284(38)$ & $390(22)$ & $<0.001$ & 1.00 & $<0.001$ & $<0.001$ \\
\hline $\mathrm{PCl}$ & $381(9.4)$ & $183(12)$ & $97(13)$ & $101(5.8)$ & $<0.001$ & 1.00 & $<0.001$ & $<0.001$ \\
\hline CABG & $50(1.2)$ & $22(1.4)$ & $12(1.6)$ & $16(0.9)$ & 0.26 & & & \\
\hline
\end{tabular}

Data given as $\mathrm{n}(\%)$, mean \pm SD or median (IQR). ${ }^{\dagger}$ Sodium $<135 \mathrm{mEq} / \mathrm{dL}$. $\neq$ World Health Organization criteria (hemoglobin $<12 \mathrm{~g} / \mathrm{dL}$ for women and $<13 \mathrm{~g} / \mathrm{dL}$ for men). BNP, brain-type natriuretic peptide; BT, body temperature; CABG, coronary artery bypass grafting; eGFR, estimated glomerular filtration rate; NPPV, non-invasive positive pressure ventilation; NT-proBNP, N-terminal pro brain-type natriuretic peptide; PCI, percutaneous coronary intervention; SBP, systolic blood pressure. Other abbreviations as in Table 1. 


\begin{tabular}{|c|c|c|c|c|c|c|c|c|}
\hline & \multirow{2}{*}{$\begin{array}{c}\text { Entire } \\
\text { cohort } \\
(n=4,056)\end{array}$} & \multirow{2}{*}{$\underset{(n=1,551)}{\text { HFrEF }}$} & \multirow{2}{*}{$\begin{array}{l}\text { HFmrEF } \\
(n=746)\end{array}$} & \multirow{2}{*}{$\begin{array}{c}\text { HFpEF } \\
(n=1,744)\end{array}$} & \multicolumn{4}{|c|}{ P-value } \\
\hline & & & & & & $\begin{array}{l}\text { HFmrEF } \\
\text { vs. HFrEF }\end{array}$ & $\begin{array}{c}\text { HFpEF } \\
\text { vs. HFrEF }\end{array}$ & $\begin{array}{l}\text { HFmrEF } \\
\text { vs. HFpEF }\end{array}$ \\
\hline \multicolumn{9}{|l|}{ In-hospital mortality } \\
\hline Death from any cause & $271(6.7)$ & $142(9.2)$ & $36(4.8)$ & $89(5.1)$ & $<0.001$ & 0.001 & $<0.001$ & 1.00 \\
\hline Cardiovascular death & $203(5.0)$ & $114(7.4)$ & $28(3.8)$ & $58(3.3)$ & $<0.001$ & 0.002 & $<0.001$ & 1.00 \\
\hline Cardiac death & $190(4.7)$ & $107(6.9)$ & $26(3.5)$ & $54(3.1)$ & $<0.001$ & 0.003 & $<0.001$ & 1.00 \\
\hline Death from HF & $165(4.1)$ & $90(5.8)$ & $24(3.2)$ & $48(2.8)$ & $<0.001$ & & & \\
\hline Sudden death & $16(0.4)$ & $13(0.8)$ & $2(0.3)$ & $1(0.1)$ & 0.002 & & & \\
\hline Other cardiac death & $9(0.2)$ & $4(0.3)$ & 0 & $5(0.3)$ & 0.35 & & & \\
\hline Vascular death & $13(0.3)$ & $7(0.5)$ & $2(0.3)$ & $4(0.2)$ & 0.51 & & & \\
\hline Death related to stroke & $10(0.2)$ & $5(0.3)$ & $2(0.3)$ & $3(0.2)$ & 0.68 & & & \\
\hline Non-cardiovascular death & $68(1.7)$ & $28(1.8)$ & $8(1.1)$ & $31(1.8)$ & 0.38 & & & \\
\hline \multicolumn{9}{|l|}{ In-hospital adverse events } \\
\hline VT/VF & $208(5.5)$ & $130(9.0)$ & 27 (3.9) & $51(3.1)$ & $<0.001$ & $<0.001$ & $<0.001$ & 1.00 \\
\hline Worsening HF & $789(19)$ & $392(25)$ & $142(19)$ & $255(15)$ & $<0.001$ & 0.003 & $<0.001$ & 0.02 \\
\hline Worsening RF & $1,307(35)$ & $417(30)$ & $291(41)$ & 597 (37) & $<0.001$ & $<0.001$ & 0.001 & 0.08 \\
\hline \multicolumn{9}{|l|}{ Length of hospital stay (days) } \\
\hline Median & $16(11-25)$ & $16(11-25)$ & $16(11-24)$ & $16(11-25)$ & 0.20 & & & \\
\hline Mean & $21 \pm 18$ & $22 \pm 20$ & $21 \pm 18$ & $20 \pm 17$ & 0.07 & & & \\
\hline
\end{tabular}

Data given as $\mathrm{n}(\%)$, mean $\pm \mathrm{SD}$, or median (IQR). ${ }^{\dagger}$ Moderate or severe bleeding according to the Global Utilization of Streptokinase and Tissue Plasminogen Activator for Occluded Coronary Arteries (GUSTO) classification. RF, renal failure. Other abbreviations as in Table 1.

have non-consecutive enrollment of patients, due to the pre-defined inclusion/exclusion criteria. ${ }^{2}$ In the present $\mathrm{KCHF}$ registry, we collected very comprehensive data in all consecutive patients hospitalized with ADHF including those with acute coronary syndrome, renal failure, anemia, or infectious diseases in multiple centers in a prospective manner. ${ }^{15}$ Consequently, this is the first "all-comer" registry and the most up-to-date registry collecting various outcomes after the recent guidelines for HF have been available. The median age of 80 years in this registry was notably higher than that in all the previous large registries on ADHF (Table S5). ${ }^{6-12}$ In addition, the information on physical, living, and socioeconomic status derived from the present registry would be important not only for health-care providers, but also for patients, their family members, and policy-makers. ${ }^{\mathbf{1 5}}$

In the stable chronic condition, the features of $\mathrm{HFmrEF}$ were more similar to those of HFpEF. ${ }^{22}$ Data on HFmrEF, however, are scarce in patients with ADHF in Japan. Many features of the HFmrEF group fell between those of the $\mathrm{HFrEF}$ and $\mathrm{HFpEF}$ groups. Of the previous representative $\mathrm{HF}$ studies examining the clinical characteristics of $\mathrm{HFmrEF}, 3$ were acute $\mathrm{HF}$ registries (OPTIMIZE-HF, ${ }^{23}$ GWTG-HF, ${ }^{24,25}$ ALARM-HF ${ }^{26}$ ), 1 was a chronic HF registry in Japan (CHART-2) ${ }^{27}$ and 1 was a randomized controlled trial for acute HF (PROTECT trial;28 Table S6). Similar to these studies, the age of the HFmrEF patients was in between the ages of the HFrEF and the HFpEF patients in the present study. The trend that ischemic etiology was less frequent in $\mathrm{HFpEF}$ compared with $\mathrm{HFrEF}$ and HFmrEF, and the trend that hypertensive etiology was more frequent in HFmrEF and HFpEF compared with HFrEF, were also observed in all of these studies. In the chronic HF registry, the HFmrEF patients mainly transitioned out of the HFrEF category. ${ }^{27,29}$ In contrast, clinical presentations and in-hospital mortality of the HFmrEF patients were similar to those observed in the
HFpEF patients in the present study, consistent with other acute HF studies. ${ }^{21-23}$ The in-hospital management and medication at discharge in the HFmrEF patients were in between that in the HFrEF group and that in the HFpEF group in the present study. Whether the present HFmrEF patients transitioned out of HFrEF or HFpEF remains unknown. Whether they transitioned to HFrEF or HFpEF in the course of treatment for acute HF is also currently unknown, because we and other researchers did not collect data on the changes in LVEF during hospitalization. - $^{-12}$ Given that LVEF change was recognized at 3 months after medical intervention if $\mathrm{LV}$ reverse remodeling was achieved the early phase, ${ }^{30}$ the present longitudinal cohort study describes the 6-month changes. In conjunction with these data, the information on the characteristics and management of HFmrEF patients in acute $\mathrm{HF}$ settings could provide insight into the chronic management of patients with $\mathrm{HF}$.

Factors that characterized LVEF category across all 4 quartiles of age were as follows: prevalence of female sex; AF/AFL; anemia; underlying heart disease; SBP; and BNP level. SBP at presentation was high in HFmrEF as well as in HFpEF. According to the baseline presentations, inhospital management and medication at discharge differed with LVEF category, even if stratified by age. The differences in social factors, cognitive function, and physical function observed in each LVEF category were not observed when stratified by age. To determine their phenotypes and what factors would influence the prognosis, there is a need for a longitudinal follow-up study of patient status including cardiac function and an investigation into the long-term prognosis of these patients. ${ }^{22,31}$

There are several limitations in this study. First, this study presented comprehensive cross-sectional observational data of the KCHF registry without long-term follow-up data. We did not perform analysis on the predictors of morbidity and mortality. Clinical questions about care in the elderly will be addressed in future studies through analysis of 


\begin{tabular}{|c|c|c|c|c|c|c|c|c|}
\hline & \multirow{2}{*}{$\begin{array}{c}\text { Entire } \\
\text { cohort } \\
(n=3,785)\end{array}$} & \multirow{2}{*}{$\begin{array}{c}\text { HFrEF } \\
(n=1,409)\end{array}$} & \multirow{2}{*}{$\begin{array}{c}\text { HFmrEF } \\
(n=710)\end{array}$} & \multirow{2}{*}{$\begin{array}{c}\text { HFpEF } \\
(n=1,655)\end{array}$} & \multicolumn{4}{|c|}{ P-value } \\
\hline & & & & & & $\begin{array}{l}\text { HFmrEF } \\
\text { vs. HFrEF }\end{array}$ & $\begin{array}{l}\text { HFpEF } \\
\text { vs. HFrEF }\end{array}$ & $\begin{array}{l}\text { HFmrEF } \\
\text { vs. HFpEF }\end{array}$ \\
\hline \multicolumn{9}{|l|}{ Discharge laboratory values } \\
\hline eGFR (mL/min/1.73 m²) & $43(29-59)$ & $45(31-61)$ & $43(26-59)$ & $41(29-57)$ & $<0.001$ & 0.01 & $<0.001$ & 1.00 \\
\hline eGFR $<30 \mathrm{~mL} / \mathrm{min} / 1.73 \mathrm{~m}^{2}$ & $964(26)$ & $327(24)$ & $207(30)$ & $425(26)$ & 0.01 & 0.01 & 0.36 & 0.25 \\
\hline Hyponatremia $^{\dagger}$ & $470(13)$ & $190(14)$ & $79(11)$ & $207(13)$ & 0.34 & & & \\
\hline Anemia $^{\ddagger}$ & $2,600(70)$ & $862(63)$ & $490(71)$ & $1,239(76)$ & $<0.001$ & $<0.001$ & $<0.001$ & 0.02 \\
\hline \multicolumn{9}{|l|}{ Medication at discharge } \\
\hline No. prescribed drugs & $8(6-11)$ & $9(6-11)$ & $8(7-11)$ & $8(6-11)$ & 0.18 & & & \\
\hline RAAS inhibitors & $2,806(74)$ & $1,116(79)$ & $529(75)$ & $1,156(70)$ & $<0.001$ & 0.04 & $<0.001$ & 0.06 \\
\hline ACEI/ARB & $2,176(57)$ & $910(65)$ & $404(57)$ & $858(52)$ & $<0.001$ & 0.002 & $<0.001$ & 0.07 \\
\hline ACEI & $928(25)$ & $490(35)$ & $160(23)$ & $276(17)$ & $<0.001$ & $<0.001$ & $<0.001$ & 0.002 \\
\hline ARB & $1,265(33)$ & $427(30)$ & $245(35)$ & $591(36)$ & 0.006 & 0.15 & 0.005 & 1.00 \\
\hline MRA & $1,707(45)$ & $735(52)$ & $314(44)$ & $656(40)$ & $<0.001$ & 0.002 & $<0.001$ & 0.11 \\
\hline$\beta$-blockers & $2,502(66)$ & $1,093(78)$ & $507(71)$ & $898(54)$ & $<0.001$ & 0.005 & $<0.001$ & $<0.001$ \\
\hline Calcium channel blockers & $1,298(34)$ & $311(22)$ & 267 (38) & $714(43)$ & $<0.001$ & $<0.001$ & $<0.001$ & 0.04 \\
\hline Loop diuretics & $3,063(81)$ & $1,160(82)$ & $566(80)$ & $1,329(80)$ & 0.24 & & & \\
\hline Thiazide & $222(5.9)$ & $64(4.5)$ & $36(5.1)$ & $121(7.3)$ & 0.003 & 1.00 & 0.004 & 0.13 \\
\hline Tolvaptan & $402(11)$ & $173(12)$ & $58(8.2)$ & $169(10)$ & 0.01 & 0.01 & 0.21 & 0.36 \\
\hline Digoxin & $215(5.7)$ & $90(6.4)$ & $30(4.2)$ & $95(5.7)$ & 0.13 & & & \\
\hline Amiodarone & $251(6.6)$ & $154(11)$ & $43(6.1)$ & $50(3.0)$ & $<0.001$ & $<0.001$ & $<0.001$ & 0.002 \\
\hline \multicolumn{9}{|l|}{ Living situation after discharge } \\
\hline Home & $3,079(82)$ & $1,201(86)$ & $571(81)$ & $1,304(79)$ & $<0.001$ & 0.002 & $<0.001$ & 1.00 \\
\hline Hospital & 459 (12) & $138(10)$ & $95(13)$ & $225(14)$ & 0.004 & 0.047 & 0.004 & \\
\hline Institution for the aged & $183(4.9)$ & 45 (3.2) & $37(5.2)$ & $100(6.1)$ & 0.001 & 0.08 & $<0.001$ & 1.00 \\
\hline Other & $25(0.7)$ & $7(0.5)$ & $5(0.7)$ & $13(0.8)$ & 0.62 & & & \\
\hline \multicolumn{9}{|l|}{ Daily life activities at discharge } \\
\hline Ambulatory & $2,738(74)$ & $1,077(78)$ & $516(73)$ & $1,137(70)$ & $<0.001$ & 0.03 & $<0.001$ & 0.37 \\
\hline $\begin{array}{l}\text { Use of wheelchair } \\
\text { (outdoor only) }\end{array}$ & $356(9.6)$ & $117(8.5)$ & $62(8.8)$ & $177(11)$ & 0.06 & & & \\
\hline $\begin{array}{l}\text { Use of wheelchair } \\
\text { (outdoor and indoor) }\end{array}$ & $488(13)$ & $149(11)$ & $90(13)$ & $247(15)$ & 0.002 & 0.57 & 0.001 & 0.37 \\
\hline Bedridden & $138(3.7)$ & $34(2.5)$ & $38(5.4)$ & $65(4.0)$ & 0.003 & 0.002 & 0.06 & 0.40 \\
\hline \multicolumn{9}{|l|}{$\begin{array}{l}\text { Use of long-term care insurance } \\
\text { at discharge }\end{array}$} \\
\hline Care required & 859 (34) & $252(28)$ & $166(33)$ & 459 (39) & $<0.001$ & 0.07 & $<0.001$ & 0.06 \\
\hline Support required & $355(14)$ & $108(12)$ & $80(16)$ & $175(15)$ & 0.03 & 0.07 & 0.11 & 1.00 \\
\hline Plan to use & $150(5.9)$ & $60(6.7)$ & $29(5.9)$ & $61(5.3)$ & 0.39 & & & \\
\hline
\end{tabular}

Data given as $\mathrm{n}(\%)$ or median (IQR). ${ }^{+}$Sodium $<135 \mathrm{mEq} / \mathrm{dL}$. $\neq$ World Health Organization criteria (hemoglobin $<12 \mathrm{~g} / \mathrm{dL}$ for women and $<13 \mathrm{~g} / \mathrm{dL}$ for men). ACEI, angiotensin-converting enzyme inhibitors; ARB, angiotensin-receptor blockers; MRA, mineralocorticoid receptor antagonists; RAAS, renin-angiotensin-aldosterone system. Other abbreviations as in Table 1.

background, in-hospital management, and improvement or worsening of patient status. Second, we did not perform statistical comparisons between the present data and data from other registries. Finally, there were no pre-specified criteria for hospital admission and the use of i.v. drugs for $\mathrm{HF}$-specific treatment, which were left to the discretion of the attending physician.

\section{Conclusions}

This registry elucidated the contemporary clinical features and clinically relevant in-hospital outcomes of consecutive patients with ADHF in real-world clinical practice and presented the clinical features of HFrEF, HFmrEF, and HFpEF populations in Japan. Significant differences in characteristics and in-hospital outcomes existed between patients with HFrEF, HFmrEF, and HFpEF.

\section{Acknowledgments}

Everyone who contributed significantly to this work is listed in Appendix S1.

\section{Funding}

None.

\section{Disclosures}

T. Kimura serves as an advisory board member for Abbott Vascular and Terumo Company. The other authors declare no conflicts of interest.

\section{References}

1. Benjamin EJ, Blaha MJ, Chiuve SE, Cushman M, Das SR, Deo R, et al. Heart disease and stroke statistics-2017 update: A report 
from the American Heart Association. Circulation 2017; 135: e146-e603.

2. Ambrosy AP, Fonarow GC, Butler J, Chioncel O, Greene SJ, Vaduganathan $\mathrm{M}$, et al. The global health and economic burden of hospitalizations for heart failure: Lessons learned from hospitalized heart failure registries. J Am Coll Cardiol 2014; 63: $1123-1133$.

3. Shimokawa H, Miura M, Nochioka K, Sakata Y. Heart failure as a general pandemic in Asia. Eur J Heart Fail 2015; 17: 884 892.

4. Heidenreich PA, Albert NM, Allen LA, Bluemke DA, Butler J, Fonarow GC, et al. Forecasting the impact of heart failure in the United States: A policy statement from the American Heart Association. Circ Heart Fail 2013; 6: 606-619.

5. Christ M, Störk S, Dörr M, Heppner HJ, Müller C, Wachter R, et al. Heart failure epidemiology 2000-2013: Insights from the German Federal Health Monitoring System. Eur J Heart Fail 2016; 18: 1009-1018.

6. Adams KF, Fonarow GC, Emerman CL, LeJemtel TH, Costanzo MR, Abraham WT, et al. Characteristics and outcomes of patients hospitalized for heart failure in the United States: Rationale, design, and preliminary observations from the first 100,000 cases in the Acute Decompensated Heart Failure National Registry (ADHERE). Am Heart J 2005; 149: 209-216.

7. Gheorghiade M, Abraham WT, Albert NM, Greenberg BH, O'Connor CM, She L, et al. Systolic blood pressure at admission, clinical characteristics, and outcomes in patients hospitalized with acute heart failure. JAMA 2006; 296: 2217-2226.

8. Allen LA, Fonarow GC, Liang L, Schulte PJ, Masoudi FA, Rumsfeld JS, et al. Medication initiation burden required to comply with heart failure guideline recommendations and hospital quality measures. Circulation 2015; 132: 1347-1353.

9. Nieminen MS, Brutsaert D, Dickstein K, Drexler H, Follath F, Harjola VP, et al. EuroHeart Failure Survey II (EHFS II): A survey on hospitalized acute heart failure patients: Description of population. Eur Heart J 2006; 27: 2725-2736.

10. Atherton JJ, Hayward CS, Wan Ahmad WA, Kwok B, Jorge J, Hernandez AF, et al. Patient characteristics from a regional multicenter database of acute decompensated heart failure in Asia Pacific (ADHERE International-Asia Pacific). J Card Fail 2012; 18: 82-88.

11. Lee SE, Cho HJ, Lee H, Yang H, Choi JO, Jeon E, et al. A multicentre cohort study of acute heart failure syndromes in Korea: Rationale, design, and interim observations of the Korean Acute Heart Failure (KorAHF) registry. Eur J Heart Fail 2014; 16: 700-708.

12. Sato N, Kajimoto K, Keida T, Mizuno M, Minami Y, Yumino $\mathrm{D}$, et al. Clinical features and outcome in hospitalized heart failure in Japan (from the ATTEND Registry). Circ J 2013; 77: 944-951.

13. Okura Y, Ramadan MM, Ohno Y, Mitsuma W, Tanaka K, Ito $\mathrm{M}$, et al. Impending epidemic: Future projection of heart failure in Japan to the year 2055. Circ J 2008; 72: 489-491.

14. Hamaguchi S, Yokoshiki H, Kinugawa S, Tsuchihashi-Makaya M, Yokota T, Takeshita A, et al. Effects of atrial fibrillation on long-term outcomes in patients hospitalized for heart failure in Japan: A report from the Japanese Cardiac Registry of Heart Failure in Cardiology (JCARE-CARD). Circ J 2009; 73: 20842090.

15. Yamamoto E, Kato T, Ozasa N, Yaku H, Inuzuka Y, Tamaki Y, et al. Kyoto Congestive Heart Failure (KCHF) study: Rationale and design. ESC Heart Fail 2017; 4: 216-223.

16. McKee PA, Castelli WP, McNamara PM, Kannel WB. The natural history of congestive heart failure: The Framingham study. N Engl J Med 1971; 285: 1441-1446.

17. Senni M, Tribouilloy CM, Rodeheffer RJ, Jacobsen SJ, Evans JM, Bailey KR, et al. Congestive heart failure in the community: A study of all incident cases in Olmsted county, Minnesota, in 1991. Circulation 1998; 98: 2282-2289.

18. Butler J, Gheorghiade M, Kelkar A, Fonarow GC, Anker S, Greene SJ, et al. In-hospital worsening heart failure. Eur J Heart Fail 2015; 17: 1104-1113.

19. Filippatos G, Farmakis D, Parissis J. Renal dysfunction and heart failure: Things are seldom what they seem. Eur Heart $J$ 2014; 35: 416-418.

20. Vardeny O, Wu DH, Desai A, Rossignol P, Zannad F, Pitt B, et al. Influence of baseline and worsening renal function on efficacy of spironolactone in patients with severe heart failure: Insights from RALES (Randomized Aldactone Evaluation Study). $J$ Am Coll Cardiol 2012; 60: 2082-2089.
21. Clark H, Krum H, Hopper I. Worsening renal function during renin-angiotensin-aldosterone system inhibitor initiation and long-term outcomes in patients with left ventricular systolic dysfunction. Eur J Heart Fail 2014; 16: 41-48.

22. Hsu JJ, Ziaeian B, Fonarow GC. Heart failure with mid-range (borderline) ejection fraction: Clinical implications and future directions. JACC Heart Fail 2017; 5: 763-771.

23. Fonarow GC, Stough WG, Abraham WT, Albert NM, Gheorghiade M, Greenberg BH, et al. Characteristics, treatments, and outcomes of patients with preserved systolic function hospitalized for heart failure: A report from the OPTIMIZE-HF Registry. J Am Coll Cardiol 2007; 50: 768-777.

24. Cheng RK, Cox M, Neely ML, Heidenreich PA, Bhatt DL, Eapen ZJ, et al. Outcomes in patients with heart failure with preserved, borderline, and reduced ejection fraction in the Medicare population. Am Heart J 2014; 168: 721-730.

25. Kapoor JR, Kapoor R, Ju C, Heidenreich PA, Eapen ZJ, Hernandez AF, et al. Precipitating Clinical factors, heart failure characterization, and outcomes in patients hospitalized with heart failure with reduced, borderline, and preserved ejection fraction. JACC Heart Fail 2016; 4: 464-472.

26. Farmakis D, Simitsis P, Bistola V, Triposkiadis F, Ikonomidis I, Katsanos S, et al. Acute heart failure with mid-range left ventricular ejection fraction: Clinical profile, in-hospital management, and short-term outcome. Clin Res Cardiol 2017; 106: 359-368.

27. Tsuji K, Sakata Y, Nochioka K, Miura M, Yamauchi T, Onose $\mathrm{T}$, et al. Characterization of heart failure patients with mid-range left ventricular ejection fraction: A report from the CHART-2 Study. Eur J Heart Fail 2017; 19: 1258-1269.

28. Tromp J, Khan MAF, Mentz RJ, O'Connor CM, Metra M, Dittrich HC, et al. Biomarker profiles of acute heart failure patients with a mid-range ejection fraction. JACC Heart Fail 2017; 5: $507-517$.

29. Rastogi A, Novak E, Platts AE, Mann DL. Epidemiology, pathophysiology and clinical outcomes for heart failure patients with a mid-range ejection fraction. Eur J Heart Fail 2017; 19: $1597-1605$.

30. Ikeda $Y$, Inomata $T$, Iida $Y$, Iwamoto-Ishida $M$, Nabeta $T$, Ishii $\mathrm{S}$, et al. Time course of left ventricular reverse remodeling in response to pharmacotherapy: Clinical implication for heart failure prognosis in patients with idiopathic dilated cardiomyopathy. Heart Vessels 2016; 31: 545-554.

31. Shah KS, Xu H, Matsouaka RA, Bhatt DL, Heidenreich PA, Hernandez AF, et al. Heart failure with preserved, borderline, and reduced ejection fraction. J Am Coll Cardiol 2017; 70: $2476-2486$.

\section{Supplementary Files}

\section{Supplementary File 1}

\section{Supplementary Methods}

Supplementary Discussion

Appendix S1. Kyoto Congestive Heart Failure Steering Committee Members

Figure S1. Kyoto Congestive Heart Failure Registry hospitals.

Figure S2. Distribution of age in (A) the entire cohort and patients with heart failure (HF) with (B) reduced ejection fraction (HFrEF), (C) mid-range ejection fraction (HFmrEF), or (D) preserved ejection fraction (HFpEF).

Table S1. Patient characteristics vs. age quartile and LVEF category

Table S2. Post-hoc analysis of patient characteristics vs. LVEF category and age quartile

Table S3. Patient characteristics, clinical presentation, and inhospital management

Table S4. Clinical outcomes, clinical status, and medication at hospital discharge

Table S5. Previous representative ADHF registries and $\mathrm{KCHF}$ registry

Table S6. KCHF registry: comparison with other studies according to LVEF category

Please find supplementary file(s);

http://dx.doi.org/10.1253/circj.CJ-17-1386 